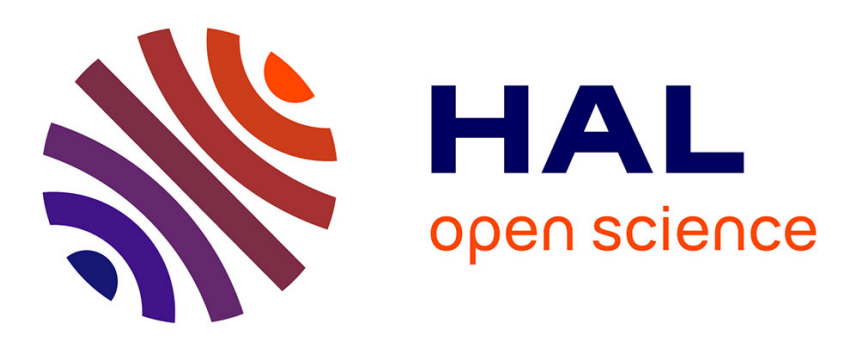

\title{
The effect of finite microscopic liquid solute diffusion on macrosegregation formation
}

\author{
K O Tveito, M. Bedel, Miha Založnik, H. Combeau, M. M'Hamdi
}

\section{To cite this version:}

K O Tveito, M. Bedel, Miha Založnik, H. Combeau, M. M'Hamdi. The effect of finite microscopic liquid solute diffusion on macrosegregation formation. IOP Conference Series: Materials Science and Engineering, 2012, 27, 10.1088/1757-899X/27/1/012040 . hal-01710322

\section{HAL Id: hal-01710322 \\ https://hal.univ-lorraine.fr/hal-01710322}

Submitted on 15 Feb 2018

HAL is a multi-disciplinary open access archive for the deposit and dissemination of scientific research documents, whether they are published or not. The documents may come from teaching and research institutions in France or abroad, or from public or private research centers.
L'archive ouverte pluridisciplinaire HAL, est destinée au dépôt et à la diffusion de documents scientifiques de niveau recherche, publiés ou non, émanant des établissements d'enseignement et de recherche français ou étrangers, des laboratoires publics ou privés. 


\section{The effect of finite microscopic liquid solute diffusion on macrosegregation formation}

To cite this article: K O Tveito et al 2012 IOP Conf. Ser.: Mater. Sci. Eng. 27012040

View the article online for updates and enhancements.
Related content
Numerical study of the impact of inoculant and grain transport on macrosegregation and microstructure formation during solidification of an $\mathrm{Al}-22 \% \mathrm{Cu}$ alloy K O Tveito, M Bedel, M Založnik et al.
Modeling of macrosegregation and solidification microstructure for Al-Si alloy under unidirectional solidification by a coupled cellular automaton - finite volume model
Hongwei Zhang, Keiji Nakajima, Engang Wang et al.
Influence of transport mechanisms on nucleation and grain structure formation in DC cast aluminium alloy ingots M Bedel, M Založnik, A Kumar et al. 


\title{
The effect of finite microscopic liquid solute diffusion on macrosegregation formation
}

\author{
K O Tveito ${ }^{1}$, M Bedel $^{2}$, M Založnik ${ }^{2}$, H Combeau ${ }^{2}$ and M M'Hamdi ${ }^{1,3}$ \\ ${ }^{1}$ Dept. of Materials Technology, NTNU, N-7491 Trondheim, Norway \\ ${ }^{2}$ Institut Jean Lamour, Departement SI2M, CNRS - Nancy-Université - UPV-Metz, \\ Ecole des Mines de Nancy, Parc de Saurupt CS 14234, F-54042 Nancy cedex, France \\ ${ }^{3}$ SINTEF Materials and Chemistry, N-0314 Oslo, Norway \\ E-mail: knut.tveito@material.ntnu.no
}

\begin{abstract}
We study the effect of solidification kinetics, driven by local limited diffusion in the liquid, on macrosegregation. If the diffusion in the liquid surrounding a growing grain is slow, the local average liquid concentration is lower than the thermodynamic equilibrium concentration at the interface. The redistribution of solute by the flow of intergranular liquid on the macroscopic scale is affected by the modified microsegregation in the liquid. We study this phenomenon using a two-phase model based on the volume-averaging method, describing macroscopic transport coupled to a microscopic grain growth model. The growth kinetics is resolved by accounting for finite diffusion in the liquid and solid phases, assuming an equiaxed globular morphology. To accurately model the diffusion field around the grain, we propose an improved approximation for the solutal boundary layer thickness accounting for the growth conditions and liquid convection. The effect of growth kinetics on macrosegregation is then investigated in the case of solidification of a binary alloy in a small cavity where the solid phase is fixed and fluid flow is driven by natural convection. We show that it is important to accurately model the diffusion field around the grain to capture correctly the effect of growth kinetics on the weakening of macrosegregation.
\end{abstract}

\section{Introduction}

Macrosegregations i.e. heterogeneities of composition at the scale of a product constitute a severe defect. Pushed by the motivation to reduce and to understand their formation, many studies have been devoted to this topic. With the "Local Solute Redistribution Equation" - (LSRE) Flemings [1] proposed the first quantitative explanation for the macrosegregation induced by the motion of the interdendritic liquid through a fixed solid matrix in a mushy zone. The LSRE is based on total and solute mass balances, simplified by assuming locally perfect mixing in the liquid phase. This implies that locally the solute concentration of the liquid is assumed to follow thermodynamic equilibrium that is maintained at the solid/liquid interfaces. Flemings showed that the orientation of the component of the liquid velocity parallel to the thermal gradient determines the development of the macrosegregation.

Later on, the use of volume averaging and of the mixture theory [2] allowed the description of the heat, mass, and momentum transport phenomena with a single-domain approach. These micro-macro models were extended to account for the type of microstructure: columnar or equiaxed; and of morphology: globular and dendritic. The influence of limited solute diffusion both in the liquid and solid phases was addressed. Such extensions allowed to describe the solidification kinetics, and thus, to model phenomena like the competition between nucleation and growth [3], the columnar to equiaxed transition [4], and the globular-dendritic morphology transition [5]. However, the consequence of local imperfect mixing of the liquid (and thus a departure from the interface Published under licence by IOP Publishing Ltd 
equilibrium concentration) on macrosegregation has not been studied in detail. The goal of the present work is to investigate and to explain the effect of the solidification kinetics, driven by local limited diffusion in the liquid, on macrosegregation. The study is, up to now, limited to simple globular microstructures.

The consequence of a limited diffusion of solute in the liquid surrounding a growing grain is a locally inhomogeneous concentration in the liquid. The state of the liquid thus deviates from thermodynamic equilibrium (constitutional undercooling or superheating), which is maintained at the grain interface. The LSRE is thus no longer valid. The deviation of the interdendritic liquid from the local thermodynamic equilibrium depends strongly of the solute flux at the solid-liquid interface. The intensity of this flux is mainly driven by the specific surface area of the interface, which is known for globular structures, and by the concentration gradient at the interface. As coupled micro-macro modeling requires simplified descriptions of the local microscopic phenomena, the concentration gradient is usually approximated by the ratio of the difference between the concentration in the phase at the interface, the average solute concentration of the phase, and of the diffusion length. Different relations have been proposed to evaluate this diffusion length. Some of them $[5,6]$ account for enhanced mixing due to convection of the liquid, but assume a steady-state situation, and neglect the motion of the interface. In case of globular structures none of them, to our best knowledge, accounted for the motion of the solid-liquid interface.

In the first part of our work we develop and propose a new diffusion length relation that accounts for both: the motion of the solid-liquid interface and the convection of the liquid. We validate it for purely diffusive situations. In a second part we investigate the effect of limited local diffusion in the liquid on macrosegregation in the case of a simple situation of solidification in a rectangular domain. We demonstrate the importance of tackling both the motion of the interface, and the convection in the diffusion length modelling.

\section{Model description and new diffusion length expression}

The volume-averaged two-phase multiscale model is described in detail in [7, 8], and only modifications carried out in the present study are presented. Grain motion is not taken into account, and nucleation occurs at the liquidus temperature: by instantaneously activating a constant predefined grain density. The growing solid structures are assumed to have a spherical shape, which can correspond to globular grains. At the microscopic level, phase change is in the model controlled by solute diffusion in both phases at the grain scale, assuming local thermal equilibrium and thermodynamic equilibrium at the solid-liquid interface. However, the set of equations, describing the local solute diffusion in the liquid and the solid phases, the solute mass balance at the interface, thermodynamic equilibrium of the liquid phase in a binary alloy and the local heat balance is time consuming to solve directly. In the adopted approach, the solute flux $J_{i}$ into phase $i$ at the solid-liquid interface is calculated in the following manner:

$$
J_{i}=S \rho_{i} D_{i} \frac{C_{i}^{*}-\left\langle C_{i}\right\rangle^{i}}{\delta_{i}}
$$

$\delta_{i}$ is the diffusion length, $S$ the interface specific surface area, $D_{i}$ the diffusion coefficient in phase $i, C_{i}^{*}$ the solute concentration in phase $i$ at the interface, $\left\langle C_{i}\right\rangle^{i}$ the average solute concentration in phase $i$. Thus, only the solute concentration at the interface and the average concentration need to be known. The solute flux is then determined by the diffusion length. To obtain an analytical expression for the diffusion length, simplifying assumptions about the solute diffusion around a growing spherical grain are necessary. Until now, different expressions were proposed for analytical liquid diffusion length: some take into account convection as in [6], others consider the velocity of the growing grain [9], but none of them accounts for both phenomena. In the present work, a new model is proposed to estimate more properly the solute exchange in the liquid at the interface, by accounting for these two phenomena assuming: i) that the product $r C$ (with $\mathrm{r}$ the radius in meters) does not vary with time in the frame attached to the grain surface, and ii) that at the microscopic scale, convection can be neglected in comparison with diffusion in a zone close to the interface, called the stagnant film, with a thickness $\Delta$. Beyond that, convection becomes predominant, the solute is mixed well and the concentration, 
therefore, homogeneous. With these hypotheses, we obtain an analytical solution of the concentration field that gives the following diffusion length:

$$
\begin{aligned}
& \delta_{l}=\frac{C_{l}^{*}-\left\langle C_{l}\right\rangle^{l}}{-\partial C_{l} /\left.\partial n\right|^{*}}=d\left\{\frac{d}{R^{*}}-\frac{f\left(R^{*}, \Delta\right)+g\left(R_{f}, R^{*}, \Delta\right)}{d\left[R^{*}+d-\left(R^{*}+\Delta+d\right) e^{-\Delta / d}\right]-f\left(R^{*}, \Delta\right)+g\left(R_{f}, R^{*}, \Delta\right)\left(e^{-\Delta / d}-1\right)}\right\}^{-1} \\
& d=D_{l} / V(t), f\left(R^{*}, \Delta\right)=\left[\left(R^{*}+\Delta\right)^{2}-R^{2}\right] / 2, g\left(R_{f}, R^{*}, \Delta\right)=\left[R_{f}^{3}-\left(R^{*}+\Delta\right)^{3}\right] /\left[3\left(R^{*}+\Delta\right)\right]
\end{aligned}
$$

where $C_{l}$ is liquid composition, $n$ is the direction normal to the interface, $D_{l}$ is the diffusion coefficient in the liquid, $V(t)$ the interface velocity at time $t$, with $R^{*}$ the grain radius, $R_{f}$ the final grain radius and $\Delta$ the stagnant film thickness. To determine $\Delta$, we use the Sherwood expression defined by Rowe et Claxton [10], which is valid for flow over spheres of similar size in regular rhombohedral or cubic arrangement, or in random packing:

$$
\begin{gathered}
S h=\frac{2}{1-g_{s}^{1 / 3}}+\frac{2}{3\left(1-g_{s}\right)} S c^{1 / 3} R e^{n(R e)}=S h_{\text {diff }}+S h_{\text {conv }} \\
S c=\frac{v}{D_{l}}, \quad R e=\frac{g_{l}\left(2 R^{*}\right)\left|\left\langle\vec{v}_{l}\right\rangle^{l}-\left\langle\vec{v}_{s}\right\rangle^{s}\right|}{v}, \quad n(R e)=\frac{2 R e^{0.28}+4.65}{3\left(R e^{0.28}+4.65\right)}
\end{gathered}
$$

Where $S c$ is the Schmidt number, Re is the Reynolds number, $v$ the kinematic viscosity $\left(\mathrm{m}^{2} / \mathrm{s}\right)$, and $\left\langle v_{l}\right\rangle^{l}$ and $\left\langle v_{s}^{\mathrm{r}}\right\rangle^{s}$ is the intrinsic velocity of the liquid and solid phase, respectively. The diffusion length around a sphere is linked to the Sherwood number by definition as: $\delta_{l}=2 R^{*} / S h$. Although the relation between $\delta_{l}$ and $\Delta$ is not known a priori, it is here set to $\Delta=2 R^{*} / S h_{\text {conv }}$, where $S h_{\text {conv }}$ is the contribution of convection to the solute flux. If the stagnant film thickness is smaller than the half-distance between grains $\Delta<R_{f} R^{*}$, Equation (2) is used for the diffusion length, otherwise diffusion is assumed to be dominant everywhere and the original analytical solution for diffusion around a growing sphere without the correction for convection is used.

\section{Test of the new diffusion length expression}

To test the model we propose, hereafter referred as "stagnant film model", the maximum undercooling obtained is compared to three other models from the literature. The first one, called "fixed front model", uses the diffusion length expression from [6], where the interface is considered stationary and the Reynolds number goes to zero. The second model, called "moving front model", was developed by C.Y. Wang and C. Beckermann [9], where a finite growth velocity $V(t)$ is taken into account but no convection is considered.

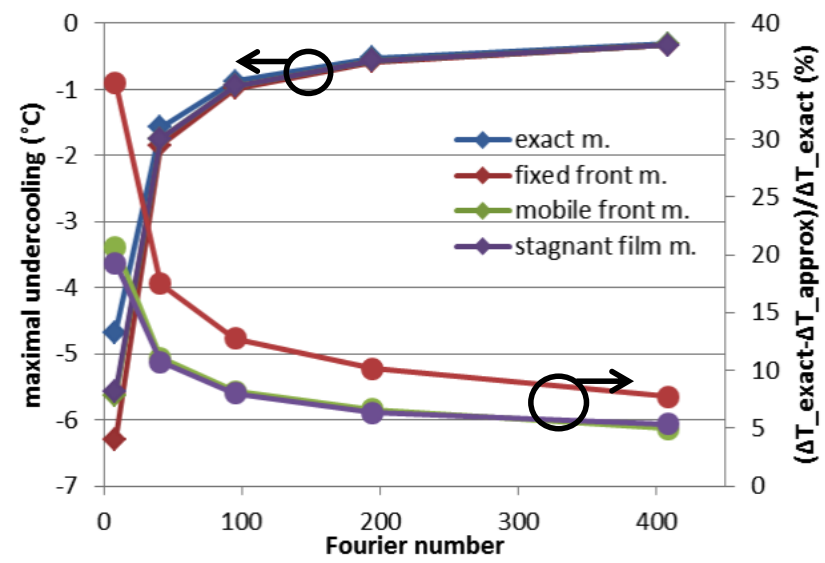

a)

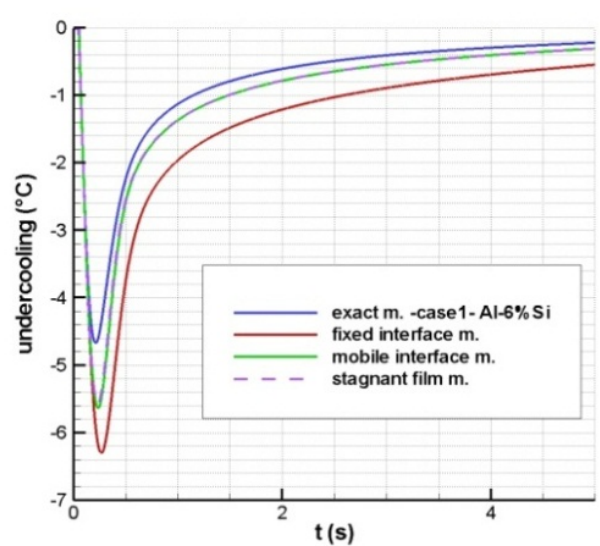

b)

Figure 1. a) Dependence of max. undercooling on the liquid Fourier number for the 4 models (squares) and dependence of the max. undercooling estimation error compared with the exact solution on the liquid Fourier number (circles) and b) example of undercooling evolution with time for the case $\mathrm{Fo}=8$ for the 4 models, for $\mathrm{Al}-6 \% \mathrm{Si}$ 
These models are also compared with a reference model, or "exact model", developed by L. Thuinet [11], which numerically solves the full equations describing the transient diffusion-controlled growth of a spherical grain and thus gives the exact diffusion length.

Comparisons are made for the solidification of an $\mathrm{Al}-6 \% \mathrm{Si}$ alloy for which the maximal undercooling reaches several degrees. A range of heat extraction rates is studied, which enables to study the impact of the Fourier number on recalescence estimation $\left(F_{O}=D_{l} t_{\text {sol }} R_{f}{ }^{2}\right.$ with $t_{\text {sol }}$ the average solidification time of grain of radius $R_{f}$; the Fourier was varied from 8 to 408 ; the values of the five cases roughly correspond to the case studied later in the macroscopic computations (table 1)).

Figure 1, by providing the relative error between the exact model solution and the approximate models, shows that the proposed model provides an estimation of the undercooling which is much better than the fixed front model and slightly better than the mobile front model. Moreover, when the heat extraction rate is decreased, the relative error is reduced. However, differences with the exact solution are still important. Indeed, the maximum undercooling occurs during the initial transient growth stage, which is neglected in the present model. But for this purely diffusive case, the model behaves as well as the moving front model (in particular for the lower range of Fourier numbers). The proposed model will be tested in the case of convection in the next part.

\section{Problem definition and numerical details of macrosegregation cases}

The problem at hand is a two-dimensional ingot casting problem where a cavity is cooled from the left and right-hand boundaries, while the top and bottom boundaries are thermally insulated. The cavity is initially filled with a stagnant liquid metal at a uniform temperature and composition. The symmetry of the problem reduces the computational domain as shown in Figure 2. The thermophysical properties of the Al-6\% Si alloy are given in Table 1.

The problem is discretized with the Finite Volume Method and the SIMPLE-method for staggered grid is used for pressure-velocity coupling. The convective terms are discretized with a $1^{\text {st }}$ order upwind scheme, and for the time discretization a fully implicit first-order scheme is used. The computational mesh consists of 3200 equidistant cells and the time step is $5.0 \times 10^{-4} \mathrm{~s}$.

Table 1. Thermophysical data Al-6wt.\%Si alloy

\begin{tabular}{lccc}
\hline Property & Unit & Value & Ref. \\
\hline Density & $\mathrm{kg} \mathrm{m}^{-3}$ & 2387.0 & \\
Specific heat & $\mathrm{J} \mathrm{kg}^{-1} \mathrm{~K}^{-1}$ & 1000.0 & \\
Thermal conductivity, solid & $\mathrm{W} \mathrm{m}^{-1} \mathrm{~K}^{-1}$ & 150.0 & {$[12]$} \\
Thermal conductivity, liquid & $\mathrm{W} \mathrm{m}^{-1} \mathrm{~K}^{-1}$ & 70.0 & {$[12]$} \\
Diffusion coefficient, solid & $\mathrm{m}^{2} \mathrm{~s}^{-1}$ & $1.74 \times 10^{-12}$ & {$[13]$} \\
Diffusion coefficient, liquid & $\mathrm{m}^{2} \mathrm{~s}^{-1}$ & $2.33 \times 10^{-9}$ & {$[13]$} \\
Latent heat of pure Al & $\mathrm{J} \mathrm{kg}^{-1}$ & $3.98 \times 10^{5}$ & \\
Liquid dynamic viscosity & $\mathrm{Pa} \mathrm{s}^{-1}$ & $1.146 \times 10^{3}$ & {$[12]$} \\
Thermal expansion coefficient & $\mathrm{K}^{-1}$ & $1.0 \times 10^{-4}$ & {$[14]$} \\
Solutal expansion coefficient & $\mathrm{wt} . \%^{-1}$ & $-4.0 \times 10^{-4}$ & {$[14]$} \\
Permeability constant & $\mathrm{m}^{2}$ & $5.55 \times 10^{-11}$ & \\
Pure Al melting temperature & ${ }^{\circ} \mathrm{C}$ & 660 & {$[15]$} \\
Al-Si eutectic temperature & ${ }^{\circ} \mathrm{C}$ & 577 & {$[16]$} \\
Liquidus slope & ${ }^{\circ} \mathrm{C} \mathrm{wt. \%}{ }^{-1}$ & -7.1 & {$[15]$} \\
Partition coefficient & - & 0.14 & {$[15]$}
\end{tabular}

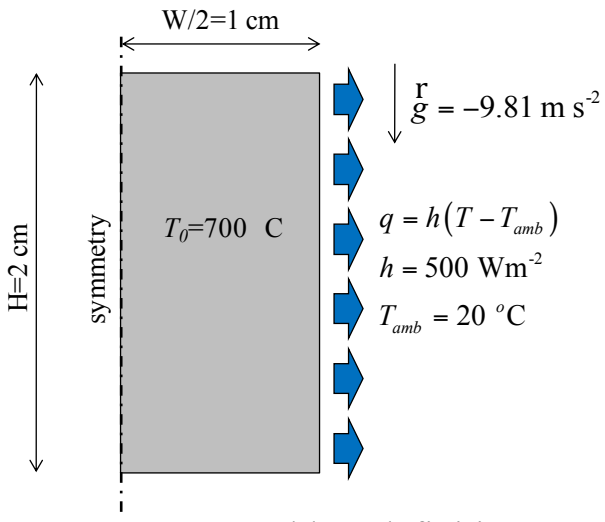

Figure 2. Problem definition

\section{Results and discussion}

The impact of growth kinetics on macrosegregation is studied with seven cases as defined in Table 2 . The Fourier number is varied by adjusting the final grain size. As $R_{f}$ increases, the characteristic length for diffusion increases and the Fourier number decrease accordingly. The limiting cases of infinite diffusion in the liquid phase, Lever Rule and Gulliver-Scheil approximations, are included as the last two cases.

The final macrosegregation pattern is shown in Figure 3 for cases 1-2, Gulliver-Scheil Case and lever rule Case. The difference between the Lever Rule Case and Gulliver-Scheil Case demonstrates 
the effect of the diffusion in the solid. It is seen that the macrosegregation intensity is slightly higher for the Gulliver-Scheil Case due to the more pronounced microsegregation; the overall pattern remains the same, however. Only very small differences are observed between Lever Rule Case, Gulliver-Scheil Case and cases 2-5, and the latter are, therefore, not presented in detail. The effect of growth kinetics becomes more significant for Case 1 , where there is a larger reduction in macrosegregation as the undercooling becomes significant. The macrosegregation pattern is also shown for Case $1 \mathrm{~b}$, where the effect of convection is not taken into account in determination of the diffusion length $(\mathrm{Re}=0$ in equation (2)). By neglecting the effect of convection, the undercooling increases, resulting in weaker macrosegregation formation.

Table 2. Case definition

\begin{tabular}{|c|c|c|c|}
\hline & $\begin{array}{c}\text { Final grain } \\
\text { size }\end{array}$ & $\begin{array}{l}\text { Fourier } \\
\text { number, } \\
\text { Liquid }^{4}\end{array}$ & $\begin{array}{l}\text { Fourier } \\
\text { number, } \\
\text { Solid }^{4}\end{array}$ \\
\hline & $R_{f}[\mathrm{~m}]$ & $F O_{l}$ & $F O_{s}$ \\
\hline Case 1a & $9.10 \times 10^{-5}$ & 10.7 & 0.008 \\
\hline Case 1b & \multicolumn{3}{|c|}{$\begin{array}{l}\text { (Identical to Case } 1 \mathrm{a} \text {, but effect of } \\
\text { convection on } \delta_{l} \text { is neglected, i.e. } \\
\text { imposed } \Delta=R_{f}-R^{*} \text { ) }\end{array}$} \\
\hline Case 2 & $4.08 \times 10^{-5}$ & 53.4 & 0.04 \\
\hline Case 3 & $2.67 \times 10^{-5}$ & 124.2 & 0.09 \\
\hline Case 4 & $1.87 \times 10^{-5}$ & 254.4 & 0.19 \\
\hline Case 5 & $1.29 \times 10^{-5}$ & 534.3 & 0.40 \\
\hline $\begin{array}{l}\text { Lever Rule } \\
\text { Case }\end{array}$ & - & $\infty$ & $\infty$ \\
\hline $\begin{array}{l}\text { Gulliver- } \\
\text { Scheil Case }\end{array}$ & - & $\infty$ & 0 \\
\hline
\end{tabular}

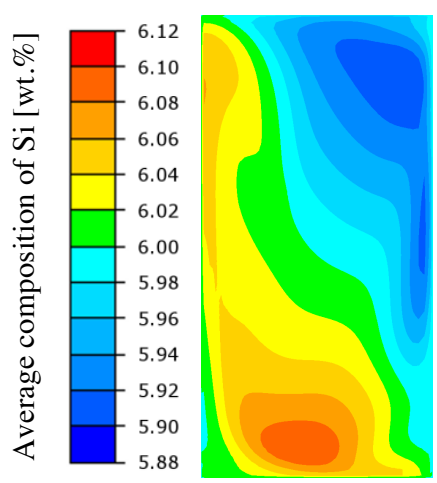

Case 1a

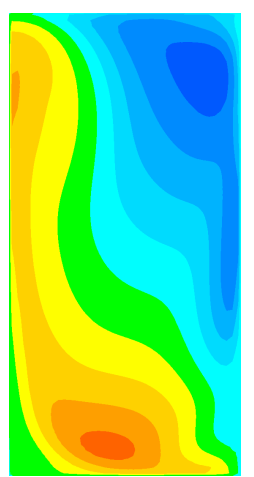

Case $1 b$

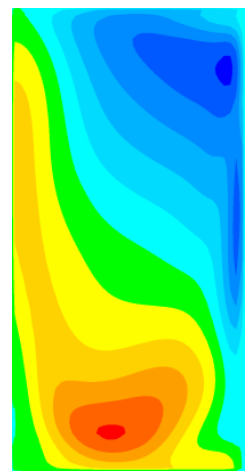

Case 2

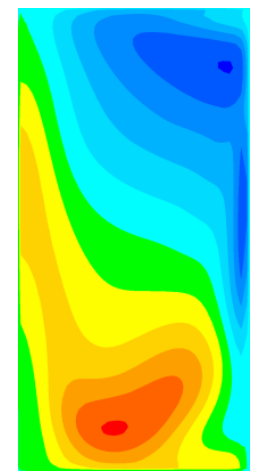

Gulliver-Scheil

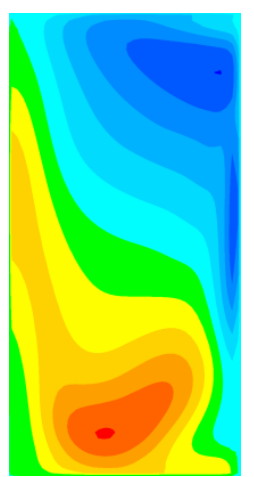

Lever Rule

Figure 3. Final macrosegregation pattern.

During solidification, a clock-wise flow pattern arises from the horizontal gradients of temperature in the cavity as the right-hand boundary is cooled. As the melt starts to solidify from the right, the liquid becomes enriched of solute and macrosegregation forms due the liquid transport. Rewriting the solute conservation equation, one can more easily explain the observed macrosegregation formation:

$$
\frac{\partial C_{m}}{\partial t}=-g_{l}\left\langle\vec{v}_{l}\right\rangle^{l} \cdot \nabla\left\langle C_{l}\right\rangle^{l}=-\frac{1}{m} g_{l}\left\langle\vec{v}_{l}\right\rangle^{l} \cdot \nabla\left[T-\Delta T_{s}\right] \quad, \quad T=T_{m}+m C_{l}^{*} \quad, \quad \Delta T_{s}=m\left(C_{l}^{*}-\left\langle C_{l}\right\rangle^{l}\right)
$$

where $C_{m}$ is the average composition, $g_{l}$ is the volume fraction liquid and $\left\langle\dot{v}_{l}\right\rangle^{l}$ the intrinsic liquid velocity. $T_{m}$ denotes the melting point of pure aluminum and $m$ is the constant liquidus slope of the linearized phase diagram. For the Lever Rule Case, the undercooling goes to zero, and the macrosegregation rate is dependent on the magnitude only, relative orientation of the temperature gradient, and the superficial liquid velocity. Due to the clock-wise flow pattern and horizontal temperature gradient, a positive macrosegregation forms in the lower part, while a negative macrosegregation is formed in the upper part. Figure 4 shows the macrosegregation rate and undercooling after $8 \mathrm{~s}$. For Case 1 the gradients of undercooling are in the same direction as the temperature gradient up to fraction solid of 0.1 and cause therefore a decrease in macrosegregation according to equation (4). However, for Case 1 the mushy zone extends much further into the cavity compared to the Lever Rule Case, causing a positive segregation along the upper part of the symmetry line. In the lower part of the cavity the greater extent of the mushy zone causes a decrease in permeability and results in a significant decrease in liquid velocity and macrosegregation rate. The 
melt convection is seen to have an impact on the growth kinetics when comparing cases $1 \mathrm{a}$ and $1 \mathrm{~b}$. As the effect of convection is neglected, the diffusion lengths become larger and the solute exchange at the interface is therefore more limited. The undercooling increases, thereby further reducing the macrosegregation.
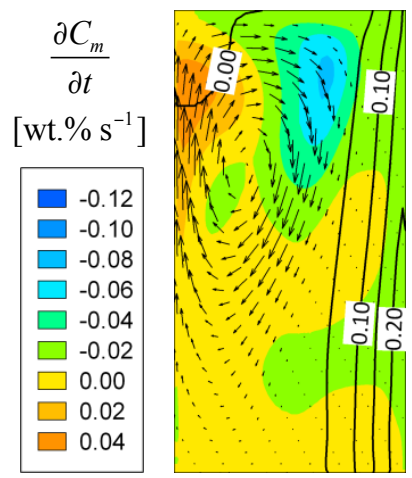

Case 1a

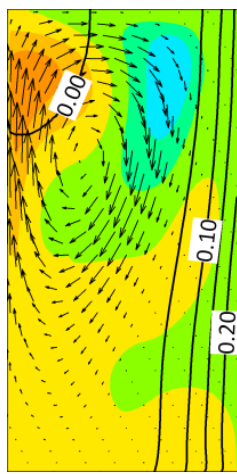

Case $1 b$

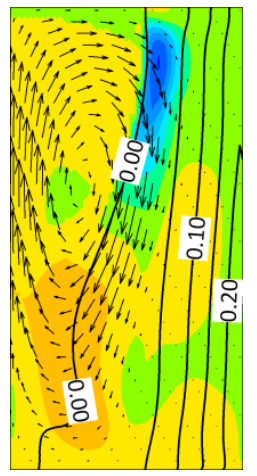

Lever Rule

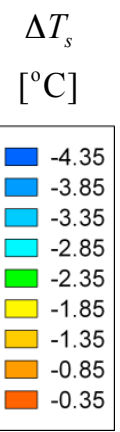

Case 1a

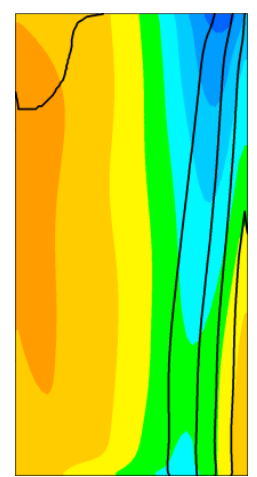

b) Solutal undercooling

a) Macrosegregation rate of $\mathrm{Si}$ and vectors of superficial liquid velocity. (Equal scale for vectors, $\mathrm{v}_{\max }=0.01 \mathrm{~m} / \mathrm{s}$ )

Figure 4. a) Macrosegregation rate for Case 1a, Case $1 b$ and Lever Rule Case and b) Solutal undercooling for Case 1a and Case $1 \mathrm{~b}$ after $8 \mathrm{~s}$. (Iso-lines of fraction solid shown from 0.001 with interval 0.05)

The overall influence of the growth kinetics is assessed by comparing the segregation index, as defined in equation (5); for all seven cases as shown in Figure 5 versus liquid Fourier number.

$$
\mathrm{SI}=\left[\frac{1}{V} \int\left(\frac{\bar{C}-C_{0}}{C_{0}}\right)^{2} d V\right]^{1 / 2} \times 100 \%
$$

By comparing the Gulliver-Scheil Case and Lever Rule Case it is seen that the overall macrosegregation formation increases only slightly as the Fourier number in the solid is decreased to zero. Going from Case 5 to Case 2 the Fourier number in the liquid and solid phases is decreased, and in this case the overall segregation decreases as the solutal undercooling increases. As the liquid Fourier number is further decreased below 50, there is a much larger decrease in macrosegregation. All the cases were also run without taking into account the effect of convection on the boundary layer. As shown in the figure, convection has a significant effect on the growth kinetics which in turn influences the macrosegregation formation.

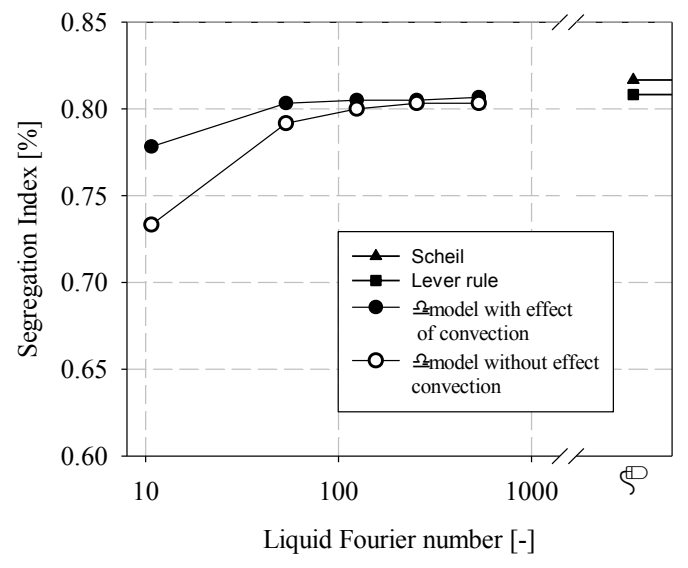

Figure 5. Segregation index as a function of liquid Fourier number

\section{Conclusion}

The effect of growth kinetics on macrosegregation has been studied for a 2D ingot casting problem. To study this effect it is important to accurately describe the liquid diffusion on a microscopic level. Therefore, an improved approximation of the diffusion length in the liquid phase around a growing globular grain is proposed. The model has been validated against the exact solution for the case of pure diffusion, showing the importance of taking the growth velocity on the microscopic diffusion into account. The study shows that the growth kinetics can have a significant impact on the 
macrosegregation formation, both through the direct influence of decreasing the enrichment of the liquid and by significantly changing the flow field. Finally, it was shown that it is important to take the effect of convection into account for predicting the growth kinetics and its effect on macrosegregation.

\section{Acknowledgement}

This research work is supported by Hydro, Alcoa Norway, Aleris, Corus and the Research Council of Norway.

\section{References}

[1] Flemings M C and Nereo G E, Trans. AIME, 1967. 239: p. 1449-1461.

[2] Beckermann C and Wang C, Annual review of heat transfer VI, 1995. 6: p. 115-198.

[3] Rappaz M and Thévoz P, Acta Metallurgica, 1987. 35(7): p. 1487-1497.

[4] Wang C and Beckermann C, Metall. Mater. Trans. A, 1994. 25(5): p. 1081-1093.

[5] Appolaire B, Combeau H, and Lesoult G, Mat. Sci. Eng.: A, 2008. 487(1-2): p. 33-45.

[6] Ni J and Beckermann C, J. Mater. Process. Manu., 1993. 2: p. 217-231.

[7] Zaloznik M and Combeau H, Comp. Mater. Sci., 2010. 48(1): p. 1-10.

[8] Zaloznik M, Kumar A, and Combeau H, Comp. Mater. Sci., 2010. 48(1): p. 11-21.

[9] Wang C Y and Beckermann C, Metall. Trans. A, 1993. 24(12): p. 2787-2802.

[10] Rowe P N and Claxton K T, Trans. Instn. Chem. Engrs, 1965. 43: p. 321-333.

[11] Thuinet L, Combeau H, Comp. Mater. Sci., 2009. 45(2): p. 294-304.

[12] Willers B, et al., Metall. Mater. Trans. B, 2008. 39(2): p. 304-316.

[13] Du Y, et al., Mat. Sci. Eng.A, 2003.363(1-2): p. 140-151.

[14] Zhou B H, et al., Advances in Space Research, 2008. 41(12): p. 2112-2117.

[15] Tøndel PA, PhD. thesis, Department of Metallurgi. 1994, NTNU: Trondheim.

[16] Effenberg G, Ilyenko S (ed.), Al-Cu-Si (Aluminium - Copper - Silicon), in SpringerMaterials The Landolt-Börnstein Database. 2005, (http://www.springermaterials.com). 